Federal Reserve Bank of Dallas

Globalization and Monetary Policy Institute

Working Paper No. 311

https://www.dallasfed.org/ /media/documents/institute/wpapers/2017/0311.pdf

\title{
Global Commodity Prices and Global Stock Volatility Shocks: Effects across Countries*
}

\author{
Wensheng Kang \\ Kent State University \\ Ronald A. Ratti \\ University of Missouri \\ Joaquin Vespignani \\ University of Tasmania
}

April 2017

\begin{abstract}
This paper investigates the time-varying dynamics of global stock volatility, commodity prices, and domestic output and consumer prices. The main empirical findings of this paper are: (i) stock volatility and commodity price shocks impact each other and the economy in a gradual and endogenous adjustment process; (ii) the impact of a commodity price shock on global stock volatility is far greater during the global financial crisis than at other times; (iii) the effects of global stock volatility on US output are amplified by the endogenous commodity price responses; (iv) in the long run, shocks to commodity prices (stock market volatility) account for $11.9 \%(6.6 \%)$ and $25.1 \%(11.6 \%)$ of the variation in US output and consumer prices; (v) the effects of global stock volatility shocks on the economy are heterogeneous across nations and relatively larger in the developed countries.
\end{abstract}

JEL codes: D80, E44, E66, F62, G10

\footnotetext{
* Wensheng Kang, Kent State University, 330 University Drive, NE. New Philadelphia, OH 44663. 330308-7414. wkang3@kent.edu. Ronald A. Ratti, Department of Economics, University of Missouri. 573884-7989. rattir@missouri.edu. Joaquin Vespignani, University of Tasmania, Tasmanian School of Business and Economics, Australia.61-3-62262825. joaquin.vespignani@utas.edu.au. The views in this paper are those of the authors and do not necessarily reflect the views of the Federal Reserve Bank of Dallas or the Federal Reserve System.
} 


\section{Global Commodity Prices and Global Stock Volatility Shocks: Effects across Countries}

\section{Introduction}

Chiarella et al. (2009) emphasize that financial market interaction with the real sector is the foundation of macroeconomic instability and is crucially important in influencing output and employment. Over the last twenty years we have witnessed extraordinary movement in global stock market volatility and in global commodity prices, particularly during the global financial crisis. Stock volatility and commodity price shocks can be expected to impact each other and to affect the macroeconomy. A growing literature has shown that higher global uncertainty reflected in stock market volatility and by other measures has been shown to depress economic activity (see for example: Sly (2016) and Kang et al (2016)). The literature has also established links between commodity prices and the real economy and asset markets. Shocks to commodity prices raise global stock volatility and cause a drop in the output and sharp rise in consumer prices. Shocks to global stock volatility depress output and consumer and commodity prices. In this paper, we develop the hypothesis that the effects of global stock volatility on outputs are amplified by the endogenous commodity price responses.

The link between stock price returns and commodity prices are well stablished by the empirical litearture. Chiarella et al. (2016) show that stock return volatility is positively related with gold futures prices and negatively related with oil prices futures. Kilian and Park (2009), documented that demand and supply global oil shocks jointly account for up to $22 \%$ of the variation in the US real stock returns. Kang et al. (2017) show that the US oil production have a positive effect on the US stock market and argue 
that both demand and supply oil shocks are important in explaining US real stock returns. Lee and Ni (2002) connect oil prices shocks with an increase in profits for the petroleum and chemicals industries, while a decrease in profit of the durable goods industries in the US. In examing the driving forces of international business cycles, Crucini et al. (2011) find a large common factor in oil prices, productivity, and the terms of trade.

In this paper we found that shocks to global stock volatility cause negative effects on US output and inflation and global commodity prices. Shocks to commodity prices raise global stock volatility and cause a drop in the output and sharp rise in consumer prices. The cumulative effects on output and consumer prices to global stock volatility and commodity shocks are largest during the period of the global financial crisis. The effects of shocks to global commodity prices on US output and consumer prices are found to be larger than the effects of shocks to global stock volatility. Stock volatility and commodity prices impact the economy in a gradual adjustment process and gives rise to strong endogenous propagation mechanism involving output and consumer prices. In the long run, shocks to commodity prices account for $11.9 \%$ and $25.1 \%$ of the variation of US industrial production and consumer prices, and shocks to global stock volatility account for $6.6 \%$ and $11.6 \%$ of the variation of US industrial production and consumer prices. Commodity price shocks forecast $32.5 \%$ of the variation of consumer prices at the 3-month horizon. Innovation to commodity prices predict $10.5 \%$ of the variation in the global stock volatility. The effect of global stock volatility and commodity price shocks have increased over time with greatest response during the global financial crisis. The impact of global stock volatility shocks are heterogeneous across economies and larger in the developed countries. 
The remainder of the paper is orgazined as follows. Section 2 introduces the theory and presents the hypothesis development. Section 3 sets out the time-varying parameter SVAR model and explains the estimation methodology. Section 4 presents the data and discuss the impulse response analysis of the estimated model. Section 5 concludes. The data source and Markov chain Monte Carlo (MCMC) algorithm are presented in the Appendix A1.

\section{The Theory and Hypothesis Development}

The model proposed by Blanchard (1981) extends Keynesian IS-LM analysis to emphasize the interaction between asset values and output. The share price dynamics feeds back on the real output from the assumption that investment/consumption demand (I) varies with Tobin's average $(Q)$ rather than the real rate of interest. Blanchard (1981) assumes that there are three main determinants of aggregate spending $(d)$ : the stock market value $(q)$, the income $(y)$ and the index of fiscal policy $(g)$; that is $d=\alpha q+$ $\beta y+g$, where the coefficients $\alpha>0$ and $0 \leq \beta<1$. Define the speed of output adjustment $k_{y}>0$, the output adjusts to changes in spending according to

$$
\dot{y}=k_{y}(d-y)
$$

where $\dot{y}$ denotes the time derivative of $y$. The stock market adjusts to excess demand for stocks

$$
\dot{q}=k_{q}(\epsilon-\bar{\epsilon}) \cdot(\epsilon-\bar{\epsilon})
$$

where $k_{q}>0$ is the speed of adjustment of the stock market to excess demand for stocks, $\epsilon=\left(x+\alpha_{0}+\alpha_{1} y\right) / q-i$ denotes the instantaneous differetial between returns on shares and returns on short-term bonds with the coefficient $\alpha_{1} \geq 0$. Here we define $x$ as 
the instantaneous expected change in the value of the stock market, and assume the existence of a long-run constant equity premium $(\vec{\epsilon})$. We assume the formation of expectations about the expected change in the value of the stock market

$$
\dot{x}=k_{x}(\dot{q}-x)
$$

where $k_{x}>0$ denotes the speed of revision of the expectations.

One key assumption in Blanchard's (1981) model is $k_{q}=\infty$ and $k_{x}=\infty$, a definite law of motion for $q$ and $x$. The dynamic law is temporarily switched off at the starting time when a shock occurs. However, Chiarella et al. (2009) argues that the reaction coefficient $k_{q}$ changes as a function of market conditions. ${ }^{1}$ A gradual adjustment of stock prices and output instead of jumps to their stable path causes the endogenous propagation mechanisms and the fluctations of stock prices and outputs. This is based on the notion that agents become more cautions as they expect a change in the market regime when a larger return differential occurs. The agents initially react along with the movement in the stock market, but they react increasingly cautiously to the return differential as the economy is moving futher from its steady state.

In the above model, the short-term interest rate $(i)$ plays an indirect role that determines the Tobin's average $(Q)$ on the stock market from the assumption of LM equilibrium in the asset market; that is $i=c y-h(m-p)$, where the coefficients $c>0$ and $h>0, m$ and $p$ the logarithms of nominal money and prices respectively. A summary of the dynamics of stock market, interest rate and output is $y \rightarrow i \rightarrow q \rightarrow I \rightarrow y$ for a given price level (see Chapter 2 in Chiarella et al. (2009)).

\footnotetext{
${ }^{1}$ The previous literature that argues $k_{q} \neq \infty$ includes Beja and Goldman (1980) and Damodaran (1993).
} 
Over recent years the literature on the relationship between commodity prices and the stock market activity has grown quite large (see Kilian and Park (2009), Johnson and Soenen (2009), Creti et al. (2013), Kang et al. (2017), and Chiarella et al (2016) among others). The literature documents that commodity price shocks and stock market volatilities are interrelated and influence the real economic activity.

Policymakers pay attention to the commodity price shocks and their potential to feed inflation pressures (Creti et al. (2013)). Positive oil-market specific demand shocks may lower real GDP and raise coonsumer prices (Kilian (2009)). Oil supply and demand shocks cause a rise in the policy-related economic uncertainty (Kang (2017)). We build on the above strands of literature to examine the following hypothesis:

Hypothesis: (i) A gradual adjustment of stock prices and output instead of jumps to their stable path causes the endogenous propagation mechanisms and the fluctations of stock prices and real output. (ii) The effects of stock prices on the output are amplified by the endogenous commodity price responses, while shocks to commodity prices cause an increase in the global stock volatility and a decrease in the output.

\section{The Empirical Model}

Our empirical model consists of a structural vector autoregression model with time-varying parameters (TVP-SVAR). Although our study is focused on different variables, the specification of the reduced-form time-varying parameter SVAR follows closely that in Primiceri (2005) and Del Negro and Primiceri (2015) as follows:

$$
y_{t}=z_{t} \beta_{t}+u_{t}
$$


where $u_{t} \sim$ iid. $N\left(0, H_{t}\right)$. The $y_{t}$ is a $m \times 1$ vector of endogenous variables, $z_{t}=$ $\left(c_{t}, y_{t-1}, \ldots, y_{t-p}\right)$ denotes a $m \times(p+1)$ matrix of $p$ lags of the endogenous variables with a constant term $c_{t}$, and $\beta_{t}=\left(\beta_{0, t}, \beta_{1, t}, \ldots, \beta_{p, t}\right)^{\prime}$ stands for the $(p+1) \times m$ matrix of the time-varying regression coefficients.

In the analysis, $y_{t}=\left(\Delta I P_{t}, \Delta C P_{t}, \Delta C P I_{t}, I R_{t}, G S V_{t}\right)^{\prime}$ where $I P_{t}$ denotes the log of industrial production, $C P_{t}$ refers to the log of commodity price index, $C P I_{t}$ stands for the $\log$ of consumer price index, $I R_{t}$ represents the short-term interest rates, and $G S V_{t}$ is the global stock volatility. We take the lags $p=12$ to allow for the potentially long-delayed effects of stock volatility shocks on the economy and to mitigate the possible serial correlation issues. As the literature shows that the greatest effect of uncertainty on real activity is expected to occur with a delay of about one year (e.g., Hamilton (2008) and Bloom (2009)).

The specification (4) allows us to investigate changes in the variance of the structural shocks in the global stock volatility/commodity prices over time and in the transmission of the global volatility/price shocks to real output over time. The global stock volatility captures the global systematic risk for securities listed in the world stock markets generated by a variety of sources across countries. It is expected to have potentially larger implication for the economic growth than do the idiosyncratic risk in individual nations. As the literature shows on the relationship between commodity prices and the stock market activity, we investigate how commodity price shocks and stock market volatilities are interrelated and influence the real economic activity based on the specification (4). 
We assume that the reduced-form innovations $u_{t}$ are a linear transformation of the underlying structural shocks $\varepsilon_{t}$ given by

$$
u_{t}=A_{t}^{-1} \Sigma_{t} \varepsilon_{t}
$$

where $\varepsilon_{t} \sim$ iid. $N\left(0, I_{m}\right)$ such that $H_{t}=A_{t}^{-1} \Sigma_{t} \Sigma_{t}^{-1}\left(A_{t}^{-1}\right)^{\prime}$. The $A_{t}$ is a lower triangular matrix, in which the non-zero and non-one elements may be stacked by rows into a $m \times(m-1) / 2$ vector as $a_{t}=\left(a_{21, t}^{\prime}, a_{31, t}^{\prime}, a_{32, t}^{\prime}, \ldots, a_{m(m-1), t}^{\prime}\right)^{\prime}$. The $\Sigma_{t}$ is a diagonal matrix, in which the non-zero elements may be stacked into a $m$-vector as $\ln \sigma_{t}=$ $\left(\ln \sigma_{1 t}, \ldots, \ln \sigma_{m t}\right)^{\prime}$ in their natural logarithm form. The law of motion for the timevarying parameters $\beta_{t}, a_{t}$ and $\ln \sigma_{t}$ evolve over time as the random walk process

$$
\begin{aligned}
& \beta_{\mathrm{t}+1}=\beta_{\mathrm{t}}+\mu_{\mathrm{t}}, \\
& a_{t+1}=a_{t}+v_{\mathrm{t}}, \\
& \ln \sigma_{\mathrm{t}+1}=\ln \sigma_{\mathrm{t}}+\eta_{\mathrm{t}},
\end{aligned}
$$

where $\mu_{\mathrm{t}}, v_{\mathrm{t}}$ and $\eta_{\mathrm{t}}$ are white noise Gaussian processes with zero mean and constant covariance matrices $Q, W$ and $S$ respectively. We assume that the error terms $\epsilon_{t}, \mu_{t}, v_{t}$ and $\eta_{t}$ are independent and are mutually uncorrelated at all leads and lags. The limiting case of the system (4) - (8) is a constant coefficient VAR model by postulating $Q, W$ and $S$ being zeros.

The identification of the stock volatility shock is inspired by the strategy proposed by Chiarella et al. (2009), while the ordering of endogenous variables follows that in Gali and Gambetti (2015). We utilize Cholesky decomposition to orthogonalize the residuals and assume that stock prices respond instantaneously to all structural shocks in the system. We assume that the stock volatility shock does not affect industrial production, commodity prices, inflation and interest rates contemporaneously within a month. Short- 
term interest rates respond immediately to own shocks and shocks to industrial production, commodity prices and inflation, but only with at least one-month delay to innovations in stock prices. Shocks to commodity prices are assumed to cause inflation within a month. While own shocks and shocks to industrial production have simultaneous effects on the price level, the industrial production does not respond contemporaneously to innovations in the price level given the sluggishness of real activity.

To compute the impulse response functions, we rewrite Equation (4) as

$$
\tilde{y}_{t}=\tilde{c}_{t}+\tilde{\beta}_{t} \tilde{y}_{t-1}+\tilde{u}_{t}
$$

where $\tilde{y}_{t}=\left(y_{t}^{\prime}, y_{t-1}^{\prime}, \ldots, y_{t-p+1}^{\prime}\right)^{\prime}, \tilde{u}_{t}=\left(u_{t}^{\prime}, 0, \ldots, 0\right)^{\prime}, \tilde{c}_{t}=\left(c_{t, 0}^{\prime}, 0, \ldots, 0\right)^{\prime}$, and the matrix of regression coefficients $\tilde{\beta}_{t}$. Define $B_{t, k}=\left(\tilde{\beta}_{t}^{k}\right)_{m \times m}$ the first $m \times m$ submatrix of $\tilde{\beta}_{t}^{k}$ for the forecasting horizons $k=1,2, \ldots$ and $B_{t, 0}=I$. The dynamic responses of the endogenous variables in $y_{t}$ to the unit structural stock volatility shock $\varepsilon_{m, t}$ at time $t$ are given by $\partial y_{t} / \partial \varepsilon_{m, t}=B_{t, k}\left[A_{t}^{-1} \Sigma_{t}\right]_{m}$ where $[Z]_{m}$ denotes the $m$-column of $Z$.

We utilize Bayesian method to estimate the SVAR model with time-varying parameters. In the Bayesian analysis, we use the first 120 observations of 10 years to calibrate the key prior hyperparameters at time $0: \beta_{0} \sim N\left(\hat{\beta}_{0}, m(p+1) \times \widehat{V}_{\beta}\right)$, $\ln \left(\sigma_{0}\right) \sim N\left(\ln \left(\hat{\sigma}_{0}\right), I_{m}\right)$, and $a_{0} \sim N\left(\hat{a}_{0}, m(m-1) \times \widehat{V}_{a}\right)$. The calibration of $\hat{\beta}_{0}$ and $\hat{V}_{\beta}$ is obtained from the conditional maximum likelihood estimates (MLE) of the regression coefficients and the elements of their variance-covariance matrix of the time-invariant SVAR model respectively. The specification of $\hat{\sigma}_{0}, \hat{a}_{0}$ and $\hat{V}_{a}$ is drawn from the decomposition of time-invariant error variance-covariance matrix $H=A^{-1} \Sigma \Sigma^{\prime}\left(A^{-1}\right)^{\prime}$. We utilize Wishart distribution priors $Q^{-1} \sim W\left(v_{Q}, V_{Q}^{-1}\right)$ where $v_{Q}=m(p+1)+1$ and $V_{Q}=0.05 \times m(p+1) \times I_{m(p+1)}, W^{-1} \sim W\left(v_{w}, V_{w}^{-1}\right)$ where $v_{w}=m+1$ and $V_{Q}=$ 
$0.0001 \times m \times I_{m}$, and $S^{-1} \sim W\left(v_{s}, V_{s}^{-1}\right)$ where $v_{s}=m(m-1)+1$ and $V_{s}=0.01 \times$ $m(m-1) \times I_{m(m-1)}$, for the constant variance-covariance matrices of the innovations in the Equations (6), (7) and (8) respectively.

Our model estimation is based on the Monte Carlo simulation of the joint posterior density $p\left(\beta^{T}, \sigma^{T}, a^{T}, Q, W, S \mid y^{T}\right)$ obtained from the combination of the prior distribution and the likelihood function of a $T$-sample. To calculate the impulse response functions of the variables to a structural shock at time $t$, we run the Markov chain Monte Carlo (MCMC) algorithm executed 22,000 times with the first 20,000 draws discarded as burn-in iterates. This Gibbs sampling algorithm follows closely that in Primiceri (2005) and Primiceri and Del Negro (2015) described in the Appendix.

\section{Data and the Empirical Evidence}

We obtain the monthly commodity price indices of energy, non-energy and precious metals from the Pink Sheet of World Bank Commodity Price Data. ${ }^{2}$ The energy index covers coal, crude oil and natural gas prices, the non-energy commodity price index includes metals, agriculture, and fertilizer prices, and the precious metal index contains gold, silver, and platinum prices. To construct the global commodity price index, we take the simple average of energy, non-energy and precious metal indices as equal weights are routinely used in the construction of commodity price index (Kilian (2009)).

This study follows Kang et al. (2016) to construct a global uncertainty index given by the first principal component of stock market volatility of the largest 15

\footnotetext{
${ }^{2}$ The monthly commodity price indices are available starting in January 1960 . The energy index is the weighted average of coal (4.7), crude oil (84.6) and natural gas prices (10.8). The non-energy index is the weighted average of metals (31.6), agriculture (64.9), and fertilizer prices (3.6), where the agriculture covers beverages, food, raw materials, cereals, fats $\&$ oils, and other food. The precious metal index is the weighted average of gold (77.8), silver (18.9), and the platinum prices (3.3).
} 
economies. ${ }^{3}$ The countries are Australia, Brazil, Canada, China, France, India, Italy, Japan, Mexico, Russia, South Korea, South Africa, United Kingdom (UK) and the United Sates (US). ${ }^{4}$ The index provides a forward-looking indicator that is implicitly weighted in accordance with the impact of different sources of uncertainty across major countries in the world on equity value.

Define $R_{c, t}$ the difference of the natural log of the stock market index of country $c, R_{c, t}=\ln \left(s_{c t} / s_{c t-1}\right)$, where $s_{c t}$ denotes the average monthly stock price of a country $c$ at time $t$, with $t=1,2 \ldots, T$. We first center on the means of $R_{c, t}$, based on the data matrix with $R_{c, t}$ for the 15 largest economies and $T$ samples; that is $V_{c, t}=\left(R_{c, t}-\bar{R}_{c}\right)^{2}$, where $V_{c, t}$ is the stock market volatility of country $c$ at time $t$, and $\bar{R}_{c}$ is the sample average of $R_{c, t}$. The first principal component for the global stock volatility $\left(G S V_{t}\right)$ is given by the linear combination of all 15 volatility indices $V_{A u s t r a l i a, t}, V_{B r a z i l, t}, \ldots, V_{U S, t}$; that is $G S V_{t}=a_{1} V_{\text {Australia }, t}+a_{2} V_{B r a z i l, t}+\cdots+a_{15} V_{U S, t}$, where $G S V_{t}$ is calculated such that it accounts for the greatest possible variance in the data set. The weights $\left(a_{i}\right)$ are the elements of an eigenvector with unit length and standardized by the unity restriction of $a_{1}^{2}+a_{2}^{2}+\cdots+a_{15}^{2}=1$. The construction of global stock volatility index closely follows that in Kang et al. (2016), whereas data definition, source and period availability of stock market index, industrial production, and the consumer price index for each country are reported in the Appendix. ${ }^{5}$

\footnotetext{
${ }^{3}$ The largest 15 economies are measured based on the 2013 gross domestic product (based on purchase power parity). Note that this first principal component accounts for around $40 \%$ of the data variation.

${ }^{4}$ Because of data limitation we exclude Indonesia, Iran, Thailand, Nigeria and Poland from the G20 economies.

${ }^{5}$ Note that data on the stock market is not available for all countries from 1981. The index is constructed with data on the countries for which data are available. A shortcoming of this approach is that for the earlier period, missing data is more apparent for developing countries. Nevertheless, we argue that this is not necessarily a problem, given that in the first part of the sample (1980-1995) the relative weight of
} 


\subsection{Responses of US variables to global stock volatility shocks}

In this subsection, we report the cumulative impulse response of the US variables to global stock volatility shocks generated by our estimated SVAR models both with constant and time-varying parameters. The cumulative responses present the dynamic effects of the differenced variables of industrial production, commodity price index and consumer price index in terms of their levels.

\subsubsection{Constant parameters}

We are first focused on the estimated responses of industrial production, commodity price index, consumer price index, and short-term interest rate to the global stock volatility shocks with 68 percent confidence intervals drawn from 2000 Bootstrapping samples. Results shown in the last column of Figure 1 are based on the estimated SVAR with constant coefficients for the US over the period 1981:M12014:M12. An unexpected innovation to global stock volatility causes statistically significant negative effects on US industrial production in a window between the $3^{\text {rd }}$ and $13^{\text {th }}$ months. Note that that terms global stock volatility and global uncertainty are used interchangeably in this manuscript.

The responses of commodity price index are mostly statistically significantly negative within a year. The decline in commodity prices to a shock to uncertainty is very marked in the first year and then gradually erodes. A shock to global stock volatility causes the consumer price index to be lower and the effect is statistically significant from the first month. This result suggests that a one-time shock to the global volatility has a significantly negative long-run effect on the consumer price level. The response in the US

developed economies in the global economy is more important than in the more recent period (following China's unprecedented growth starting in mid-1990s). The availability of stock market data for each country is reported in the Appendix. 
short-term interest rate to an unexpected rise in global stock volatility is statistically significant and negative in the window between the $3^{\text {rd }}$ and $12^{\text {th }}$ months.

The percent contributions of one-standard deviation structural shocks to the overall variability of the endogenous variables are presented in Table 1 . The forecast error variance decomposition is shown at 1, 3, 12, 24 and 60 horizons. The values in parentheses represent the absolute t-statistics based on 2000 bootstrap samples. In the long run, shocks to global stock volatility contribute to $6.6 \%, 10.5 \%$ and $11.6 \%$ of the variation of US industrial production, commodity prices and the US consumer price index respectively, and are statistically significant at the 5\% level (at the 60 month horizon as shown in the last column of Table 1).

\subsubsection{Time-varying parameters}

We now turn to results of the SVAR model with time-varying coefficients. Figure 2.1 shows the evolution of the median of the cumulative response of the variables to the global stock volatility shock at the $1^{\text {st }}, 3^{\text {rd }}, 12^{\text {th }}$ and $60^{\text {th }}$ month over 1981:M1-2014:M12. The response of US industrial production to a unit shock to global uncertainty, indicated by a global stock volatility shock, is greatest at the time of the global financial crisis, with most of the negative effect occurring after 12 months and that then persists for 60 months. The effect of global stock volatility shocks on US industrial production at the 12 and 60 month horizons increased over time up until the global financial crisis. The response of US CPI to the global stock volatility shock shows most of the negative effect occurring after 3 months which then persists for 60 months. The effect of unit global stock volatility shocks on US CPI at the 3-month horizon increased until the global financial crisis period. The largest effect of the global volatility on the interest rate has a delay of about 5 years. 
Over the period of 1981:M1-2014:M12 on US output, inflation and interest rate, the greatest responses of the variables to the global stock volatility shocks occur over 2005 to 2009.

The response of commodity prices to the global stock volatility shock occurs after three months and increases over time up until the global financial crisis. The divergence between the effect of a shock to global stock volatility to commodity prices at the 3 month and 60 month horizons has increased over time. The implication is that in the last half of the sample, the decline in commodity prices in the first three months following a shock to global stock volatility is greater and then erodes more in subsequent months than in the first half of the sample.

In summary, shocks to the global stock volatility cause a negative effect on US production, inflation and interest rate, and on commodity prices. The responses of the variables to the global volatility shock is often gradual and take time for the responses to reach its maximum. The most dramatic effects occur over the period of 2005-2009 and are particularly acute during the global financial crisis. The negative effect on US output is relatively small until the mid-1990s, with much of the effect occurring within 12 months. The changing response of the consumer price index shows an increased negative effect from the global volatility shock from 1980 s to 2000 s, especially at the 3 -month horizon. Much of the cumulative negative effect on the consumer price index happens within the 3-month horizon and this effect then persists into the long-term. Unexpected shocks to global stock volatility cause a relatively larger negative effect on the interest rate during the 2000s. Shocks to global stock volatility normally cause sharp declines in 
global commodity prices within 3 months, an effect that has increased in magnitude over time. The effect on commodity prices is then eroded within a year.

These results provide us with supporting evidence that the stock market impacts the economy in a gradual adjustment process, which in turn gives rise to strong endogenous propagation mechanism and fluctuations of both stock prices and the output (Chiarella et al, 2009). We find that the relationship between the stock market dynamics and the US macroeconomy appear to be changing over time. The changing responses of production and inflation to the global stock volatility shocks show stronger effects during the global financial crisis.

\subsection{Responses of US variables to commodity price shocks}

In this subsection, we report the cumulative impulse responses to commodity price shocks generated by models with constant and time-varying parameters. Results for the constant parameter model are shown in the diagrams in Column 2 of Figure 1. An unanticipated positive innovation in commodity prices is associated with a negative effect on US industrial production that is statistically significant after 6 months. The effect is persistent and remains statistically significant through the horizon of 60 months. A positive shock to commodity prices initiates a rise in the consumer price index immediately and the statistically significantly effect continues over the 60-month forecasting horizon. The findings that a shock to commodity prices has persistent and statistically significant effects on US production and prices are striking. In contrast, an innovation in commodity prices does not have a statistically significant effect on the short-term interest. 
The impact of an unanticipated rise in commodity prices on global stock volatility are shown in the last row and second column of Figure 1. The positive response in global stock volatility is statistically significant starting in the $6^{\text {th }}$ month and persists over the 60 months forecasting horizon. Shocks to commodity prices clearly impact and increase global stock market volatility.

The forecast error variance decomposition results in Table 1, suggest that in the long run, shocks to commodity prices account for $11.9 \%, 25.1 \%$ and $5.7 \%$ of the variation of industrial production, consumer price index and the global stock volatility. Commodity price shocks forecast $32.5 \%$ of the variation consumer prices at the 3 -month horizon. These effects are statistically significant in Table 1.

During the 2008-2009 global financial crisis (as shown in Figure 2.2), shocks to commodity prices cause a dramatic rise in the global stock volatility and a sharp drop in the US industrial production at the forecasting horizons of 12 and 60 months. The close proximity of the cumulative responses at the 12th and 60th months for industrial production and for global stock volatility confirms the persistence effects on output and global stock volatility from commodity price shocks after the first few months. The impact of a commodity price shock on global stock volatility is far greater during the global financial crisis than at other times (at the forecasting horizons of 12 and 60 months). These results suggest that the effects of global stock volatility on the US output are amplified by the endogenous commodity price responses.

The effect of a commodity price shock on consumer prices at the 60-month horizon is largest in the late 1990s, but at the 1 and 3-month horizons is largest in the mid-2000s. Prior to the year 2000 a positive shock to commodity prices had positive 
effects on consumer prices that built up over time. During 2006-2009, a period maximum impact at the 1 and 3-month horizons, the full extent of the effect of commodity price shocks on consumer prices is more or less achieved in the first month.

Figure 2.2 shows that the estimated dynamic responses of industrial production, interest rate and the global stock volatility appear to be instable and gradually rise over time. The impulse responses of consumer prices are relatively stable over time. The changing responses of US variables to commodity price shocks show different pattern from that to the global stock volatility shocks.

4.3. Heterogeneous impact of global stock volatility/commodity price shocks on the economy across countries

In this subsection, we investigate the heterogeneous impact on the output and price level, of the global stock volatility/commodity price shocks, for major countries including four developing countries (Brazil, China, India, Russia) and twelve developed countries (Australia, Canada, France, Germany, Ireland, Italy, Japan, Korea, Netherland, Spain, UK, US).

Table 2 reports the percent contributions of structural shocks to commodity prices/global stock volatility to the output and price levels across countries, based on the structural VAR model with constant coefficients and 2000 bootstrap samples. $^{6}$ In the long run, the forecast error variance decomposition shows that shocks to commodity prices account for a statistically significant variation in industrial production at the $5 \%$ level in 9 countries: Australia, Brazil, France, India, Italy, Japan, Korea, Russia and the UK. This shock also explains a statistically significant variation in the consumer price index in 10 countries: Canada, France, Germany, India, Ireland, Italy, Korea, Netherland, Spain, and

\footnotetext{
${ }^{6}$ The forecast at the $1^{\text {st }}$ month is around zero across countries and is omitted for the exposition purpose.
} 
the UK. ${ }^{7}$ Shocks to global stock volatility account for a statistically significant variation in industrial production at the 5\% level in 4 countries: Brazil, Italy, Korea, and Russia. This shock explains the variation of consumer price index for France, India, Ireland significantly in the long run.

In terms of magnitude, shocks to commodity prices account for $13.5 \%$ of the variation in industrial production in India and $14.1 \%$ of the variation in consumer price index in France respectively. The cumulative response of output and price levels to the commodity price shocks in India and France at the $12^{\text {th }}$ month in Figure 3 show a drop during the 2008-2009 global financial crisis. A unit shock to commodity prices causes $25 \%$ decreases in the industrial production in India in 12 months around October 2008 for example. $^{8}$

Shocks to global stock volatility account for $16 \%$ of the variation in industrial production in Brazil and 15.5\% of the variation in consumer price index in Ireland in the long run respectively. During the 2008-2009 global financial crisis, the negative response of output and price levels to the commodity price shocks in Brazil and Ireland at the 12th month in Figure 3 decreases. A unit shock to global stock volatility causes about $10 \%$ decreases in the consumer price index for Ireland in 12 months around October 2008 in particular. ${ }^{9}$

In summary, both shocks to global commodity prices and stock volatility show heterogenous effects on the output and price level in general. Commodity price shocks

\footnotetext{
${ }^{7}$ It is acknowledged that he significance is marginal for India.

${ }^{8}$ During the 2008-2009 global financial crisis, the responses of output and price levels to the commodity price shocks also decrease across other countries. The results are available upon request.

${ }^{9}$ The responses of output and price levels to the global stock volatility shocks also show a drop across other countries in the period of 2008-2009 global financial crisis. The results are available upon request.
} 
present broader effects on the economy across countries than do shocks to the global stock volatility. A significant global stock volatility shock is always associated with a significant commodity shock on the output/price level. Developing countries such as Brazil, India and Russia are relatively more vulnerable upon the commodity shocks. The effects of global stock volatility shocks on the economy are relatively larger in the developed countries such as Italy, Korea and the US.

\section{Conclusion}

Building on the insightful empirical work of Chiarella et al. (2009) and the theoretical framework of Blanchard (1981). This paper investigates the time-varying dynamics of global stock volatility, commodity prices, and domestic output and consumer prices. The main findings of this paper are: Shocks to global stock volatility causes negative effects on commodity prices that are statistically significant for the first year. Shocks to global commodity prices have positive effects on global stock volatility that are statistically significant and persistent. During the global financial crisis shocks to commodity prices cause a dramatic rise in the global stock volatility and a sharp drop in the US industrial production. Prior to 2000 a positive shock to commodity price had positive effects on consumer prices that built up over time. The effects of global stock volatility on the US output are amplified by the endogenous commodity price responses. Shocks to commodity prices cause large fluctuations of both output and the interest rate over time; The effects of global stock volatility shocks on the economy are heterogeneous across nations and relatively larger in the developed countries. 


\section{Reference}

Beja, A., Goldman, M.B., 1980. On the dynamic behavior of prices in disequilibrium. Journal of Finance 35, 235-248.

Blanchard, O.J., 1981. Output, the stock market, and interest rates. The American Economic Review 71, 132-143.

Bloom, N., 2009. The impact of uncertainty shocks. Econometrica 77, 623-685.

Chiarella, C., Kang., Nikitopoulos, C.S., and Tô, T., 2016. The Return-Volatility

Relation in Commodity Futures Markets," Journal of Futures Markets, 36, 127-152.

Chiarella, C., Kang, B., Nikitopoulos-Sklibosios, C., T^o, T., 2013. Humps in the volatility structure of the crude oil futures market: New evidence. Energy Economics, vol. $40989-1000$.

Chiarella, C., Flaschel, P., Franke, R., Semmler, W., 2009. Financial markets and the macroeconomy: a Keynesian perspective. Routledge International Studies in Money and Banking, Routledge.

Creti, A., Joëts, M., Mignon, V., 2013. On the links between stock and commodity markets' volatility. Energy Economics 37, 16-28.

Crucini, M.J., Kose, M.A., Otrok, C., 2011. What are the driving forces of international business cycles? Review of Economic Dynamics 14, 156-175.

Damodaran, A., 1993. A simple measure of price adjustment coefficients. Journal of Finance 48, 378-400.

Del Negro, M., Primiceri, G.E., 2015. Time varying structural vector autoregressions and monetary policy: a corrigendum. The Review of Economic Studies 82, 1342-1345.

Galí, J., Gambetti, L., 2015. The effects of monetary policy on stock market bubbles: Some evidence. American Economic Journal: Macroeconomics 7, 233-257.

Grossman, V., Mack, A., and Martinez-Garcia, E., 2014. Database of global economic indicators (DGEI): a methodological note, Globalization and Monetary Policy Institute Working Paper 166, Federal Reserve Bank of Dallas.

Hamilton, J., 2008. Oil and the Macroeconomy. New Palgrave Dictionary of Economics, 2nd edition, edited by Steven Durlauf and Lawrence Blume, Palgrave McMillan Ltd. Johnson, R., Soenen, L., 2009. Commodity prices and stock market behavior in South American countries in the short run. Emerging Markets Finance and Trade 45, 69-82. 
Kang, W., Ratti, R.A., Vespignani, J.L., 2016. The impact of global uncertainty on the global economy, and large developed and developing economies. Available at SSRN: https://ssrn.com/abstract=2908591.

Kilian, L., Park, C., 2009. The impact of oil price shocks on the US stock market. International Economic Review 50, 1267-1287.

Koop, G., Korobilis, D., 2010. Bayesian Multivariate Time Series Methods for Empirical Macroeconomics. Foundations and Trends in Econometrics 3, 267-358.

Lee, K. and S. Ni (2002). On the dynamic effects of oil price shocks: A study using industry level data. Journal of Monetary Economics, 49, 823-852.

Primiceri, G.E., 2005. Time varying structural vector autoregressions and monetary policy. Review of Economic Studies 72, 821-852.

Sly, N., 2016. Global Uncertainty and U.S. Exports, Economic Review, Federal Reserve Bank of Kansas City, issue Q II, pages 5-23. 


\section{Appendix A1: Data Source}

\begin{tabular}{lc}
\hline Panel A. Stock market indices & Period \\
\hline Australia: Standard \& Poor's/ASX 200 Index & Jan 1981- Dec 2014 \\
Brazil: BM\&F BOVESPA Index & Jan 1991- Dec 2014 \\
Canada: Toronto Stock Exchange index & Jan 1981- Dec 2014 \\
China: Shanghai Stock Exchange Composite Index & Dec 1990- Dec 2014 \\
France: France CAC 40 Stock Market Index & Jan 1987- Dec 2014 \\
Germany: Deutsche Boerse AG German Stock Index & Jan 1993- Dec 2014 \\
India: NSE CNX 100 Index & Jan 2003- Dec 2014 \\
Italy: FTSE MIB Index & Mar 2003- Dec 2014 \\
Japan: NIKKEI 225 Stock Market Index & Jul 1988- Dec 2014 \\
Mexico: Mexican Bolsa IPC Index & Dec 1991-Dec 2014 \\
Russia: Russia MICEX Stock Market Index & Jan 1994- Dec 2014 \\
South Korea: Korea Stock Exchange KOSPI Index & Jan 1990- Dec 2014 \\
South Africa: South Africa FTSE/JSE Index & Jan 2001- Dec 2014 \\
US: Standard \& Poor's 500 index & Jan 1981- Dec 2014 \\
UK: UK FTSE 100 Stock Market Index & Jan 1981- Dec 2014 \\
\hline Panel B. Industrial production, CPI and interest rate & Period \\
\hline
\end{tabular}

IP for the US: is the total industrial production excluding construction for the US Jan 1981- Dec 2014 economy

IP for advanced economies excluding the US: is the total industrial production Jan 1981- Dec 2014 excluding construction for the largest 31 advanced economies excluding the US

IP for emerging economies: is the total industrial production excluding construction Jan 1987- Dec 2014 for the largest 26 emerging economies

CPI for the US: is the headline consumer price index for the US

Jan 1981- Dec 2014

CPI for advanced economies excluding the US: is the headline consumer price index Jan 1981- Dec 2014 for the largest 31 advanced economies excluding the US

CPI for emerging economies: is the headline consumer price index for the largest Feb 1984- Dec 2014 emerging economies excluding the US

Interest rate for the US: Federal funds target rate

Jan 1981- Dec 2014

Interest rate for advanced economies excluding the US: Short-term official policy rate July 1985- Dec 2014 (maturity 3 months or less) for the largest 31 advanced economies excluding the US

Interest rate for emerging economies excluding the US: Short-term official policy rate Jan 1981- Dec 2014 (maturity 3 months or less) for the largest 26 emerging economies excluding the US

Notes: Global indicators for advanced and emerging are aggregated using US trade weights (for more detail, see: Grossman et al. (2014)). The largest economies according PPP-adjusted GDP shares from the IMF World Economic Outlook. Stock market data are drawn from Datastream 5.1. 


\section{Appendix A2: Markov chain Monte Carlo (MCMC) Algorithm}

The appendix describes the Markov chain Monte Carlo (MCMC) Algorithm for the estimation of the time-varying coefficients VAR model. Following Primiceri (2005) and Primiceri and Del Negro (2015) closely, we simulate the joint posterior density $p\left(\beta^{T}, a^{T}, \sigma^{T}, Q, W, S \mid y^{T}\right)$ from full conditionals as follows:

Step 1. Drawing reduced-form VAR parameters $\beta^{T}$

Utilizing the initial values $\beta_{0}, a_{0}, \sigma_{0}, Q, W$, and $S$ based on their prior distribution and the data $y^{T}$, we caculate $\beta_{T \mid T}$ and $P_{T \mid T}$ from the state-space model (1) and (3) by the last recursion of forward Kalman filter, where

$$
\begin{aligned}
& \beta_{t} \mid \beta_{t+1}, a^{T}, \sigma^{T}, Q, y^{t} \square N\left(\beta_{t} \mid \beta_{t \mid t+1}, P_{t \mid t+1}\right), \\
& \beta_{t \mid t+1}=E\left(\beta_{t} \mid \beta_{t+1}, y^{t}, a^{T}, \sigma^{T}, Q\right), \\
& P_{t \mid t+1}=\operatorname{Var}\left(\beta_{t} \mid \beta_{t+1}, y^{t}, a^{T}, \sigma^{T}, Q\right) .
\end{aligned}
$$

We are then able to simulate the smoothed estimates of $\beta_{t}, t=1,2, \ldots, T-1$, by backward recursions from $\beta_{T \mid T}$ and $P_{T \mid T}$, a Gibbs sampling developed in Carter and Kohn (1994).

Step 2. Drawing the hyperparameter $Q$

Note that the prior of $Q$ is the inverse-Wishard distribution $Q^{-1} \square W\left(\underline{v}_{Q}, \underline{V}_{Q}^{-1}\right)$, the posterior of $Q$ is an inverse-Wishard distribution $Q^{-1} \square W\left(\bar{v}_{Q}, \bar{V}_{Q}\right)$, where $\bar{v}_{Q}=T+\underline{v}_{Q}$ and $\bar{V}_{Q}^{-1}=\left(\underline{V}_{Q}+\sum_{t=1}^{T}\left(\alpha_{t+1}-\alpha_{t}\right)\left(\alpha_{t+1}-\alpha_{t}\right)^{\prime}\right)^{-1}$.

Step 3. Drawing the covariance elements $a^{T}$ 
The reduced-form VAR model (1) can be written as $\hat{y}_{t}=D_{t} a_{t}+\Sigma_{t} u_{t}$, where the estimate $\hat{y}_{t}=y_{t}-z_{t} \alpha_{t}$ and the matrix

$$
D_{t}=\left(\begin{array}{cccc}
0 & 0 & \cdots & 0 \\
-\hat{y}_{1, t} & 0 & \cdots & 0 \\
0 & -\hat{y}_{(1,2), t} & \ddots & \vdots \\
\vdots & \ddots & \ddots & 0 \\
0 & \cdots & 0 & -\hat{y}_{(1, \ldots, n-1), t}
\end{array}\right)
$$

where $-\hat{y}_{(1, \ldots, n-1), t}$ denotes the row vector $\left(\hat{y}_{1, t}, \hat{y}_{2, t}, \ldots, \hat{y}_{n-1, t}\right)$. Therefore, $a_{t}$ can be obtained from the state-space system of equations $\hat{y}_{t}=D_{t} a_{t}+\sum_{t} u_{t}$ and (4) by the Kalman filter and the backward recursion Gibbs sampling in the following form

$$
\begin{aligned}
& a_{i, t} \mid a_{i, t+1}, \beta^{T}, \sigma^{T}, W, y^{t} \square N\left(a_{i, t} \mid a_{i, t \mid t+1}, \Lambda_{i, t \mid t+1}\right), \\
& a_{i, t \mid t+1}=E\left(a_{i, t} \mid a_{i, t+1}, y^{t}, \beta^{T}, \sigma^{T}, W\right), \\
& \Lambda_{i, t \mid t+1}=\operatorname{Var}\left(a_{i, t} \mid a_{i, t+1}, y^{t}, \beta^{T}, \sigma^{T}, W\right),
\end{aligned}
$$

where $a_{i, t \mid t+1}$ is the $i$-th block of $a_{t}$ that is corresponding to the coefficients of the $i$-th equation $\hat{y}_{t}=D_{t} a_{t}+\Sigma_{t} u_{t}$.

Step 4. Drawing the hyperparameter $W$

Note that the prior of $W$ is the inverse-Wishard distribution $W^{-1} \square W\left(\bar{v}_{W}, \bar{V}_{W}\right)$, the posterior of $W$ is an inverse-Wishard distribution, where $\bar{v}_{W}=T+\underline{v}_{W}$ and $\bar{V}_{W}^{-1}=\left(\underline{V}_{W}+\sum_{t=1}^{T}\left(a_{t+1}-a_{t}\right)\left(a_{t+1}-a_{t}\right)^{\prime}\right)^{-1}$.

Step 5. Drawing the variance elements $\sigma^{T}$ 
The reduced-form VAR model (1) can be written as $y_{t}^{* * *}=2 \ln \sigma_{t}+e_{t}$, where $e_{i, t}=\ln \varepsilon_{i, t}^{2}, y_{i, t}^{* *}=\ln \left(\left(y_{i, t}^{*}\right)^{2}+c\right), y_{t}^{*}=A_{t}\left(y_{t}-z_{t} \beta_{t}\right)$, and a constant $c$ set to 0.001 . This transformation makes $e_{i, t}$ is independent of $e_{j, t}$ for $i \neq j$ that allows one to use the same independent mixture of normals approximation for any element of $e_{t}$. As in Kim et al. (1998), we define $s^{T}=\left(s_{1}, \ldots, s_{T}\right)^{\prime}$ as the state-indicator matrix showing in each point of time which member of the mixture of normals is used for each element of $e_{t}$. The $s^{T}$ can be updated by independently sampling each $s_{i, t}$ from the discrete density $\operatorname{Pr}\left(s_{i, t}=j \mid y_{i, t}^{* *}, \ln \sigma_{i, t}\right) \propto q_{j} f_{N}\left(y_{i, t}^{* *} \mid 2 \ln \sigma_{i, t}+m_{j}-1.2704, v_{j}^{2}\right), j=1, \ldots, 7, i=1, \ldots, n$, where $f_{N}(\cdot)$ denotes the normal density for $j$ with probability $q_{j}$, mean $m_{j}-1.2704$ and variance $v_{j}^{2}$ chosen as constants as in Kim et al. (1998) to match a number of moments of the $\log \chi^{2}(1)$ distribution. Therefore, $\sigma_{t}$ can be obtained from the statespace system of equations $y_{t}^{* * *}=2 \ln \sigma_{t}+e_{t}$ and (5) by the Kalman filter and the backward recursion Gibbs sampling in the following form

$$
\begin{aligned}
& \ln \sigma_{t} \mid \ln \sigma_{t+1}, \beta^{T}, a^{T}, S, y^{t}, s^{T} \square N\left(\ln \sigma_{t} \mid \ln \sigma_{t \mid t+1}, H_{t \mid t+1}\right), \\
& \ln \sigma_{t \mid t+1}=E\left(\ln \sigma_{t} \mid \ln \sigma_{t+1}, y^{t}, \beta^{T}, a^{T}, S, s^{T}\right), \\
& H_{t \mid t+1}=\operatorname{Var}\left(\ln \sigma_{t} \mid \ln \sigma_{t+1}, y^{t}, \beta^{T}, a^{T}, S, s^{T}\right),
\end{aligned}
$$

where the smoothed estimate of $\sigma_{t}$ can be recovered by the transformation $\sigma_{t}=\exp \left(\ln \sigma_{t} / 2\right)$

Step 6. Drawing the hyperparameter $S$ 
Note that the prior of $S$ is the inverse-Wishard distribution $S^{-1} \square W\left(\bar{v}_{S}, \bar{V}_{S}\right)$, the posterior of $S$ is an inverse-Wishard distribution, where $\bar{v}_{S}=T+\underline{v}_{S}$ and $\bar{V}_{S}^{-1}=\left(\underline{V}_{S}+\sum_{t=1}^{T}\left(\sigma_{t+1}-\sigma_{t}\right)\left(\sigma_{t+1}-\sigma_{t}\right)^{\prime}\right)^{-1}$.

Finally, we run the MCMC algorithm from Step 1 to Step 6 executed 22,000 times, with the first 20,000 draws discarded as burn-in iterates. 
Table 1. Percent contribution of one-standard deviation structural shocks to the overall variability of the endogenous variables

\begin{tabular}{|c|c|c|c|c|c|}
\hline \multicolumn{6}{|c|}{ Panel A. Industrial Production } \\
\hline Horizon & Productivity Shock & Commodity Price Shock & Price Level Shock & Interest Rate Shock & Global Uncertainty Shocks \\
\hline 1 & $1.000---$ & $0.000---$ & $0.000---$ & $0.000---$ & $0.000---$ \\
\hline 3 & $0.951(36.88)$ & $0.018(1.10)$ & $0.007(0.67)$ & $0.014(0.98)$ & $0.011(0.91)$ \\
\hline 12 & $0.797(16.55)$ & $0.082(2.36)$ & $0.039(1.71)$ & $0.021(1.20)$ & $0.062(2.05)$ \\
\hline 24 & $0.749(13.76)$ & $0.119(2.72)$ & $0.044(2.00)$ & $0.023(1.25)$ & $0.065(2.11)$ \\
\hline 60 & $0.746(13.46)$ & $0.119(2.73)$ & $0.045(2.01)$ & $0.024(1.19)$ & $0.066(2.12)$ \\
\hline
\end{tabular}

Panel B. Commodity Price Index

\begin{tabular}{|c|c|c|c|c|c|}
\hline Horizon & Productivity Shock & Commodity Price Shock & Price Level Shock & Interest Rate Shock & Global Uncertainty Shocks \\
\hline 1 & $0.015(0.85)$ & $0.985(56.96)$ & 0.000--- & 0.000--- & 0.000--- \\
\hline 3 & $0.035(1.29)$ & $0.879(16.80)$ & $0.027(1.40)$ & $0.003(0.43)$ & $0.056(1.61)$ \\
\hline 12 & $0.049(1.89)$ & $0.743(13.08)$ & $0.094(2.95)$ & $0.017(1.02)$ & $0.098(2.34)$ \\
\hline 24 & $0.055(2.12)$ & $0.726(12.64)$ & $0.096(3.07)$ & $0.018(1.03)$ & $0.104(2.50)$ \\
\hline 60 & $0.056(2.15)$ & $0.722(12.48)$ & $0.098(3.07)$ & $0.019(1.06)$ & $0.105(2.51)$ \\
\hline
\end{tabular}

Panel C. Consumer Price Index

\begin{tabular}{|c|c|c|c|c|c|}
\hline Horizon & Productivity Shock & Commodity Price Shock & Price Level Shock & Interest Rate Shock & Global Uncertainty Shocks \\
\hline 1 & $0.002(0.16)$ & $0.184(3.39)$ & $0.814(14.90)$ & $0.000---$ & 0.000--- \\
\hline 3 & $0.008(0.47)$ & $0.325(5.31)$ & $0.568(9.40)$ & $0.005(0.62)$ & $0.095(1.95)$ \\
\hline 12 & $0.050(1.84)$ & $0.275(5.09)$ & $0.540(9.69)$ & $0.017(1.14)$ & $0.119(2.38)$ \\
\hline
\end{tabular}




\begin{tabular}{lccccc}
24 & $0.054(2.01)$ & $0.259(4.95)$ & $0.541(9.81)$ & $0.029(1.53)$ & $0.117(2.46)$ \\
60 & $0.058(2.11)$ & $0.251(4.77)$ & $0.541(9.57)$ & $0.035(1.61)$ & $0.116(2.44)$ \\
\hline Panel D. Interest Rate & & & & & \\
\hline Horizon & Productivity Shock & Commodity Price Shock & Price Level Shock & Interest Rate Shock & Global Uncertainty Shocks \\
1 & $0.038(1.21)$ & $0.006(0.53)$ & $0.003(0.31)$ & $0.953(28.25)$ & $0.000---$ \\
3 & $0.064(1.45)$ & $0.004(0.33)$ & $0.001(0.12)$ & $0.912(18.37)$ & $0.019(1.29)$ \\
12 & $0.271(2.61)$ & $0.001(0.06)$ & $0.002(0.11)$ & $0.707(6.54)$ & $0.019(0.71)$ \\
24 & $0.379(2.87)$ & $0.011(0.27)$ & $0.003(0.07)$ & $0.598(4.35)$ & $0.009(0.34)$ \\
60 & $0.414(2.92)$ & $0.023(0.36)$ & $0.002(0.05)$ & $0.551(3.60)$ & $0.010(0.26)$ \\
\hline Panel E. Global Stock Volatility & & & Interest Rate Shock & Global Uncertainty Shocks \\
\hline Horizon & Productivity Shock & Commodity Price Shock & Price Level Shock & $0.000(0.06)$ & $0.983(24.51)$ \\
1 & $0.010(0.35)$ & $0.000(0.01)$ & $0.007(0.51)$ & $0.004(0.37)$ & $0.960(19.32)$ \\
3 & $0.022(0.71)$ & $0.007(0.27)$ & $0.008(0.56)$ & $0.021(0.81)$ & $0.864(15.44)$ \\
12 & $0.040(1.40)$ & $0.045(1.42)$ & $0.031(1.46)$ & $0.023(0.87)$ & $0.837(14.03)$ \\
60 & $0.044(1.55)$ & $0.057(1.66)$ & $0.057(1.67)$ & $0.041(1.74)$ & $0.834(13.79)$
\end{tabular}

Notes: Percent contributions of one-standard deviation structural shocks to the overall variability of the endogenous variables. The forecast error variance decomposition is based on the structural VAR model described in the text. The values in parentheses represent the absolute t-statistics based on 2000 bootstrap samples. 
Table 2. Percent contribution of commodity price/global stock volatility shocks to the overall variability of output and price level across countries

\begin{tabular}{|c|c|c|c|c|c|}
\hline \multirow[b]{2}{*}{ Horizon } & \multicolumn{2}{|c|}{ Commodity Price Shock } & \multicolumn{3}{|c|}{ Global Stock Volatility Shock } \\
\hline & Industrial Production & Consumer Price Index & Industrial Production & Consumer & Price Index \\
\hline \multicolumn{6}{|c|}{ Australia } \\
\hline 3 & $(1.41)$ & $(1.83)$ & $(0.90)$ & 0.014 & $(0.94)$ \\
\hline 12 & $(2.06)$ & $(2.12)$ & (1.43) & 0.020 & $(1.09)$ \\
\hline 60 & $(2.16)$ & $(1.57)$ & $(1.46)$ & 0.025 & $(0.87)$ \\
\hline \multicolumn{6}{|c|}{ Brazil } \\
\hline 3 & $0.020 \quad(0.85)$ & $(0.69)$ & $(1.68)$ & 0.000 & $(0.02)$ \\
\hline 12 & $0.091 \quad(1.83)$ & $(1.05)$ & $(2.60)$ & 0.026 & $(0.85)$ \\
\hline 60 & $(2.25)$ & $(1.21)$ & $(2.86)$ & 0.055 & $(1.38)$ \\
\hline \multicolumn{6}{|c|}{ Canada } \\
\hline 3 & $(0.59)$ & $(2.29)$ & $(0.13)$ & 0.009 & $(0.73)$ \\
\hline 12 & $0.035 \quad(1.68)$ & $(2.84)$ & $(1.75)$ & 0.044 & $(1.72)$ \\
\hline 60 & $0.044 \quad(1.84)$ & $(2.88)$ & $(1.81)$ & 0.043 & $(1.75)$ \\
\hline \multicolumn{6}{|c|}{ China } \\
\hline 3 & $(0.80)$ & $(0.97)$ & $(0.27)$ & 0.030 & (1.04) \\
\hline 12 & (1.28) & (1.70) & $(0.51)$ & 0.057 & (1.62) \\
\hline 60 & $0.081 \quad(1.55)$ & $(1.67)$ & (1.16) & 0.064 & $(1.77)$ \\
\hline \multicolumn{6}{|c|}{ France } \\
\hline 3 & $(1.68)$ & $(2.99)$ & $(0.88)$ & 0.040 & (1.60) \\
\hline 12 & $0.084 \quad(2.75)$ & $(3.71)$ & $(1.26)$ & 0.082 & $(2.27)$ \\
\hline 60 & $(2.88)$ & $(3.67)$ & (1.54) & 0.080 & $(2.28)$ \\
\hline \multicolumn{6}{|c|}{ Germany } \\
\hline 3 & $0.003 \quad(0.45)$ & $(2.27)$ & $(0.91)$ & 0.023 & $(1.39)$ \\
\hline 12 & $0.038 \quad(1.62)$ & (2.99) & (1.57) & 0.040 & $(1.85)$ \\
\hline 60 & $(1.75)$ & $(2.88)$ & $(1.65)$ & 0.035 & $(1.76)$ \\
\hline \multicolumn{6}{|c|}{ India } \\
\hline 3 & $(0.06)$ & $(0.60)$ & $(0.76)$ & 0.009 & $(0.28)$ \\
\hline 12 & $0.132 \quad(1.96)$ & $(2.10)$ & $(1.26)$ & 0.109 & $(2.22)$ \\
\hline 60 & $(2.12)$ & $(1.93)$ & $(1.35)$ & 0.118 & $(2.38)$ \\
\hline \multicolumn{6}{|c|}{ Ireland } \\
\hline 3 & $(0.28)$ & $(1.92)$ & $(0.16)$ & 0.026 & $(1.12)$ \\
\hline 12 & $(0.93)$ & $(2.30)$ & $(0.83)$ & 0.165 & $(2.33)$ \\
\hline 60 & $(0.99)$ & $(2.27)$ & $(1.01)$ & 0.155 & $(2.36)$ \\
\hline
\end{tabular}




\begin{tabular}{|c|c|c|c|c|c|c|c|c|}
\hline \multicolumn{9}{|c|}{ Italy } \\
\hline 3 & 0.006 & $(0.55)$ & 0.082 & (1.98) & 0.0265 & (1.10) & 0.032 & $(1.37)$ \\
\hline 12 & 0.047 & (1.84) & 0.120 & $(2.68)$ & 0.0759 & (1.94) & 0.058 & (1.99) \\
\hline 60 & 0.069 & $(2.34)$ & 0.099 & $(2.30)$ & 0.0852 & $(2.11)$ & 0.049 & $(1.53)$ \\
\hline \multicolumn{9}{|c|}{ Japan } \\
\hline 3 & 0.027 & (1.44) & 0.017 & (1.17) & 0.008 & $(0.53)$ & 0.003 & $(0.46)$ \\
\hline 12 & 0.081 & $(2.38)$ & 0.024 & (1.46) & 0.066 & (1.43) & 0.023 & $(1.49)$ \\
\hline 60 & 0.088 & $(2.45)$ & 0.019 & $(1.17)$ & 0.072 & $(1.54)$ & 0.021 & $(1.38)$ \\
\hline \multicolumn{9}{|c|}{ Korea } \\
\hline 3 & 0.046 & (1.78) & 0.066 & $(1.49)$ & 0.076 & $(1.57)$ & 0.000 & $(0.05)$ \\
\hline 12 & 0.103 & $(2.49)$ & 0.074 & (1.92) & 0.145 & $(2.50)$ & 0.011 & $(0.67)$ \\
\hline 60 & 0.108 & $(2.76)$ & 0.106 & $(2.25)$ & 0.154 & $(2.72)$ & 0.016 & $(0.84)$ \\
\hline \multicolumn{9}{|c|}{ Netherland } \\
\hline 3 & 0.004 & $(0.45)$ & 0.030 & $(1.15)$ & 0.007 & $(0.79)$ & 0.013 & $(0.99)$ \\
\hline 12 & 0.029 & (1.57) & 0.076 & $(2.46)$ & 0.060 & $(1.50)$ & 0.037 & $(1.45)$ \\
\hline 60 & 0.032 & $(1.71)$ & 0.067 & $(2.05)$ & 0.065 & $(1.64)$ & 0.039 & $(1.49)$ \\
\hline \multicolumn{9}{|c|}{ Russia } \\
\hline 3 & 0.044 & (1.13) & 0.005 & $(0.15)$ & 0.095 & $(1.74)$ & 0.002 & $(0.11)$ \\
\hline 12 & 0.098 & $(2.17)$ & 0.028 & $(0.71)$ & 0.087 & (1.94) & 0.073 & (1.53) \\
\hline 60 & 0.107 & $(2.54)$ & 0.058 & $(1.14)$ & 0.099 & $(2.22)$ & 0.089 & $(1.68)$ \\
\hline \multicolumn{9}{|c|}{ Spain } \\
\hline 3 & 0.026 & $(1.40)$ & 0.071 & $(2.28)$ & 0.001 & $(0.18)$ & 0.012 & $(1.10)$ \\
\hline 12 & 0.047 & (1.53) & 0.098 & (3.15) & 0.013 & $(0.75)$ & 0.038 & (1.79) \\
\hline 60 & 0.050 & $(1.61)$ & 0.081 & $(2.61)$ & 0.014 & $(0.78)$ & 0.027 & $(1.39)$ \\
\hline \multicolumn{9}{|c|}{ UK } \\
\hline 3 & 0.006 & $(0.71)$ & 0.068 & $(2.16)$ & 0.006 & $(0.63)$ & 0.010 & $(0.84)$ \\
\hline 12 & 0.031 & (1.77) & 0.117 & (3.17) & 0.020 & (1.06) & 0.033 & (1.67) \\
\hline 60 & 0.040 & $(2.10)$ & 0.095 & $(2.85)$ & 0.026 & $(1.27)$ & 0.027 & $(1.53)$ \\
\hline
\end{tabular}

Notes: Percent contributions of one-standard deviation structural shocks of commodity prices to the overall variability of the endogeneous variables. The forecast error variance decomposition is based on the structural VAR model described in the text. The values in parentheses represent the absolute t-statistics based on 2000 bootstrap samples. The forecast at the first month is around zero and is omitted for the exposition purpose. 
Figure 1. Cumulative Responses to One-Standard Deviation Structural Shocks: VAR with Constant Coefficients in US, 1981:M1-2014:M12
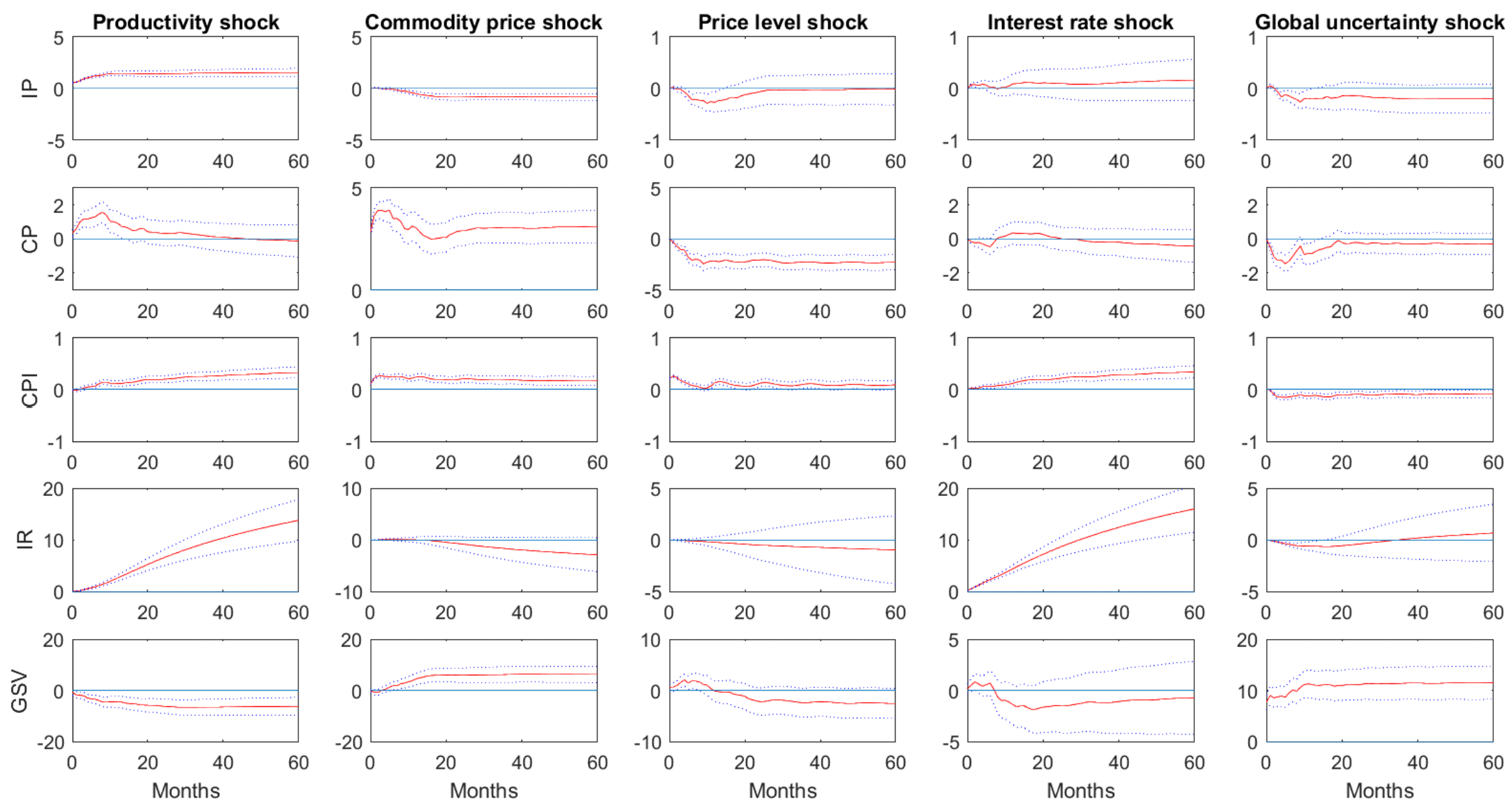
Notes: The figure shows the cumulative response of industrial production (IP), commodity price index (CP), consumer price index (CPI), short-term interest rate (IR) and the global stock volatility (GSV) to one-standard deviation structural shocks with its 68 percent confidence intervals based on 2000 Bootstrapping samples.

Figure 2.1. Cumulative Responses to Global Uncertainty Shocks: VAR with Time-Varying Coefficients in US at the $1^{\text {st }}, 3^{\text {rd }}$, $12^{\text {th }}$, and $60^{\text {th }}$ Month, 1981:M1-2014:M12
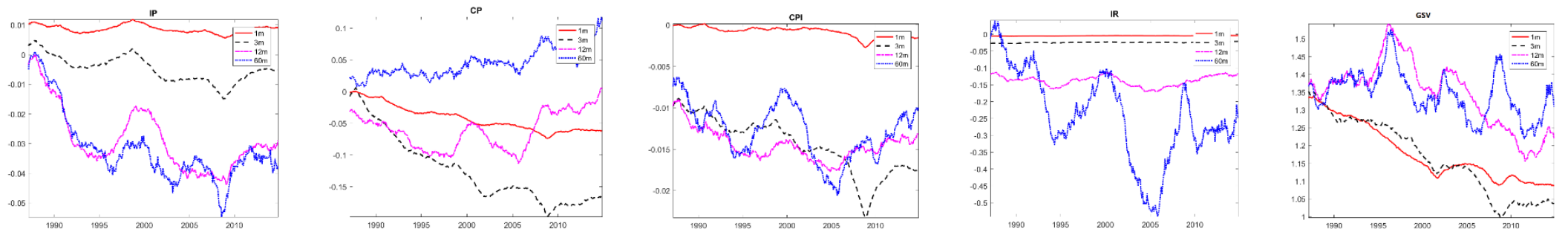

Notes: The figure shows the cumulative response of industrial production (IP), commodity price index (CP), consumer price index (CPI), short-term interest rate (IR) and the global stock volatility (GSV) to the global stock volatility shocks at the $1^{\text {st }}, 3^{\text {rd }}, 12^{\text {th }}$, and $60^{\text {th }}$ month.

Figure 2.2. Cumulative Responses to Commodity Price Shocks: VAR with Time-Varying Coefficients in US at the $1^{\text {st }}, 3^{\text {rd }}, 12^{\text {th }}$, and $60^{\text {th }}$ Month, 1981:M1-2014:M12
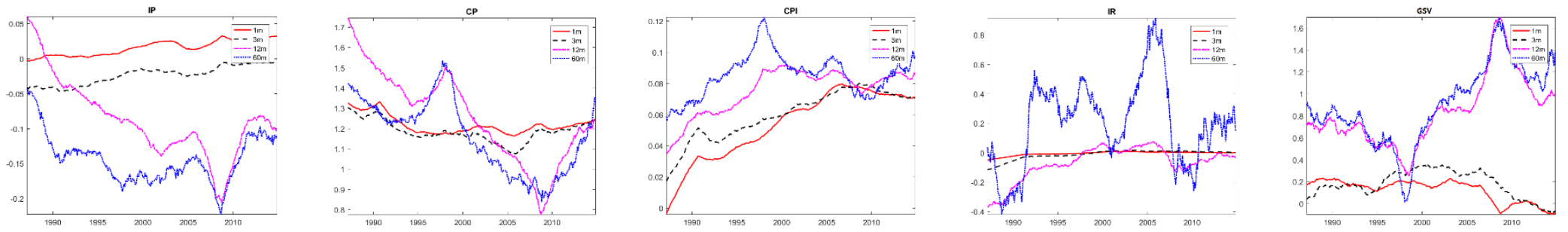

Notes: The figure shows the cumulative response of industrial production (IP), commodity price index (CP), consumer price index (CPI), short-term interest rate (IR) and the global stock volatility (GSV) to the commodity price shocks at the $1^{\text {st }}, 3^{\text {rd }}, 12^{\text {th }}$, and $60^{\text {th }}$ month. 
Figure 3. Cumulative Responses to Commodity Price/Global Uncertainty Shocks: VAR with Time-Varying Coefficients across Countries at the 12 ${ }^{\text {th }}$ Month, 1981:M1-2014:M12
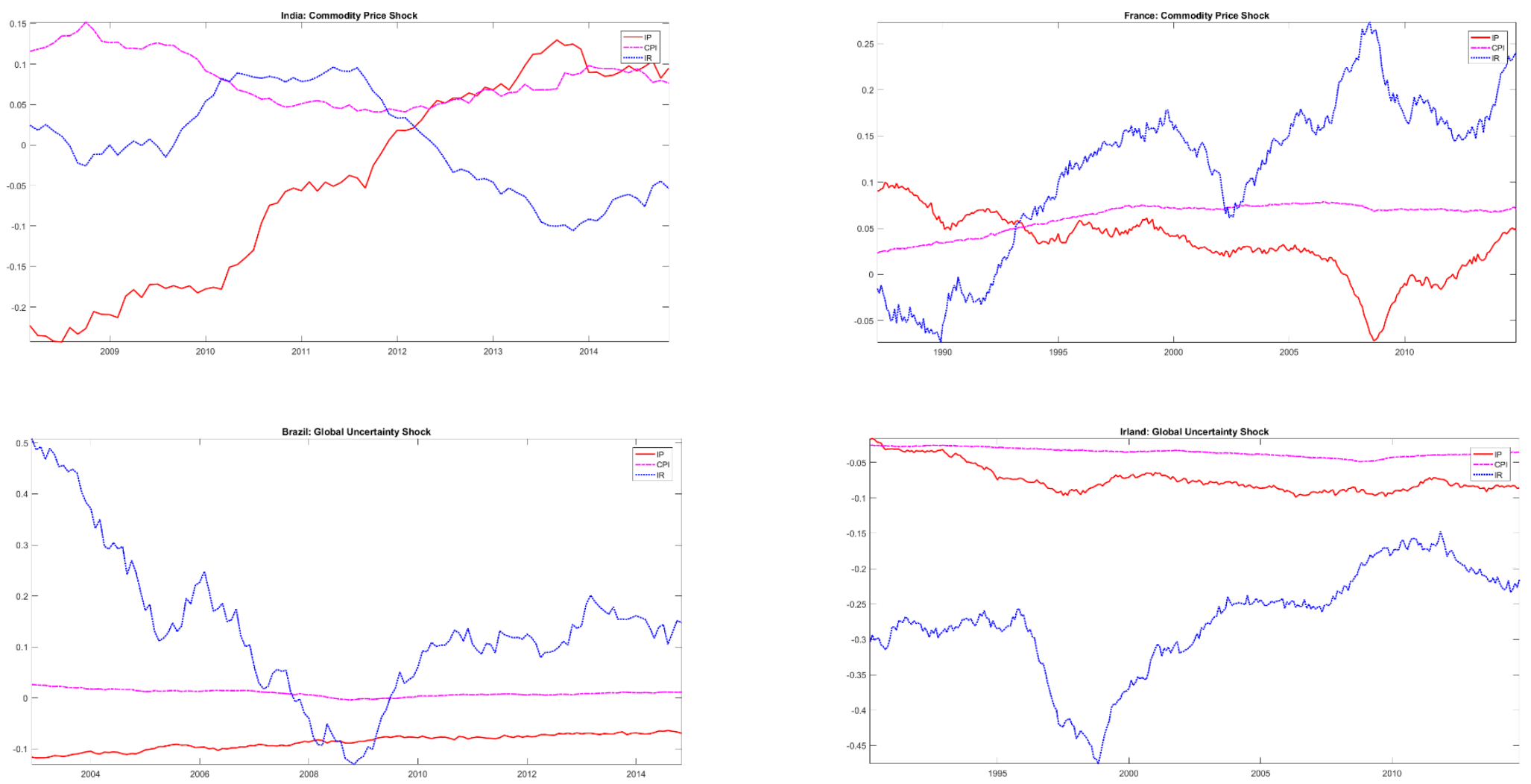

Notes: The figure shows the cumulative response of industrial production (IP), consumer price index (CPI), short-term interest rate (IR) to the commodity price/global uncertainty shocks at the $12^{\text {th }}$ month across countries. 